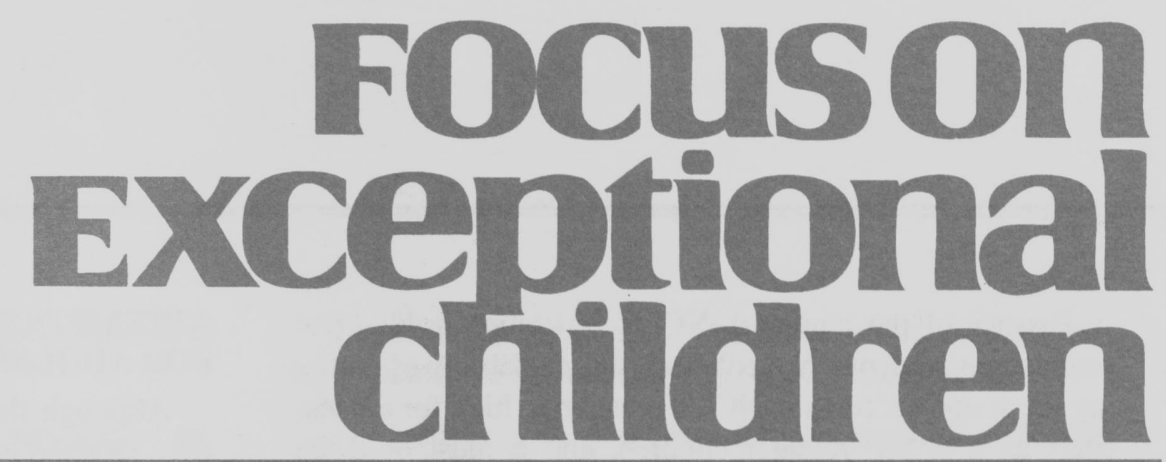

\title{
Access of Adolescents with Disabilities to General Education Curriculum: Myth or Reality?
}

\author{
Jean B. Schumaker, Donald D. Deshler, Janis A Bulgren, \\ Betsy Davis, B. Keith Lenz, and Bonnie Grossen
}

As the United States begins to implement the historic No Child Left Behind (NCLB) legislation, one thing is clear: 6 million of this country's secondary-aged students are in serious danger of being left behind. These young people live in our cities, suburbs, and rural areas and reflect all income levels. Predictably, many of these at-risk students also have a disability. Adolescents with disabilities have found the demands and expectations of high school to be especially stringent, as reflected by the findings of the National Longitudinal Transition Study (Wagner, Blackorby, \& Hebbeler, 1993). That study reported that a disproportionate number of students with disabilities (38\%) drop out of school (compared to $25 \%$ of the general population). In addition, preceding their decision to drop out of school, students with disabilities generally demonstrate higher rates of absenteeism, lower grade-point averages, and higher course-failure rates than students in the general population (Wagner et al., 1993).

In spite of these striking problems presented by the adolescent population in our schools, the vast majority of attention and resources during the past decade have been devoted to increasing early childhood education opportunities and reaching the national goal of making sure that every child possesses basic literacy skills by the third grade. Although these goals are important and laudable, there is a potential danger in overemphasizing early intervention at the expense of interventions for older students-especially those who have reached high school.

Specifically, the calls for early intervention efforts may erroneously imply that by providing early intervention, most of the problems presented by students with disabilities will be ameliorated by the time they reach adolescence. Although this is certainly a desired outcome, research has shown that the disabilities of these students persist and continue to affect their learning at older ages as well (Warner, Schumaker, Alley, \& Deshler, 1980). Thus, as compelling as the case for early intervention can be, if that case is made at the expense of addressing the equally problematic and unique set of problems presented by older students, the long-term effects of that policy will be devastating for thousands of individuals with disabilities (Deshler, 2002).

Jean B. Schumaker, Donald D. Deshler, Janis A Bulgren, Betsy Davis, B. Keith Lenz, and Bonnie Grossen are with the University of Kansas Center for Research on Learning, Lawrence, Kansas. 
Passage of the landmark NCLB legislation holds great promise for students. Nevertheless, the probability of realizing the vision set forth in NCLB must be as high for adolescents as it is for younger children, and it must hold the potential for impacting students with disabilities as much as it does for impacting students without disabilities. Regrettably, many educators report feeling overwhelmed with the task of implementing NCLB legislation across the entire age continuum (especially given the complex nature of secondary schools), and thus they have all but decided that the limited resources they have should be targeted to improving only the front end of the American educational system.

Indeed, the real tragedy is the quiet resignation that seems to pervade many education circles and the view that little, if anything, can be done for older students. In some quarters the promises inherent in NCLB do not extend to adolescents who continue to struggle to meet high standards or, worse, simply give up and leave school without a high school diploma (Alliance for Excellent Education, 2002).

\section{Focuson
Exceptional children}

ISSN 0015-511X FOCUS ON EXCEPTIONAL CHILDREN (USPS 203-360) is published monthly except June, July, and August as a service to teachers, special educators, curriculum specialists, administrators, and those concerned with the special education of exceptional children. This publication is annotated and indexed by the ERIC Clearinghouse on Handicapped and Gifted children for publication in the monthly Current Index to Journals in Education (CIJE) and the quarterly index, Exceptional Children Education Resources (ECER). The full text of Focus on Exceptional Children is also available in the electronic versions of the Education Index. It is also available in microfilm from Xerox University Microfilms, Ann Arbor, MI. Subscription rates: Individual, \$36 per year; institutions, $\$ 48$ per year. Copyright (C) 2002, Love Publishing Company. All rights reserved. Reproduction in whole or part without written permission is prohibited. Printed in the United States of America. Periodical postage is paid at Denver, Colorado. POSTMASTER: Send address changes to:

$$
\begin{gathered}
\text { Love Publishing Company } \\
\text { Executive and Editorial Office } \\
\text { P.O. Box } 22353 \\
\text { Denver, Colorado } 80222 \\
\text { Telephone (303) } 221-7333
\end{gathered}
$$

Karen Harris University of Maryland
Thomas Skrtic University of Kansas

James Shriner

University of Illinois

Erica J. Lawrence Editor
Stanley F. Love Publisher

\section{ATTEMPTS TO INCREASE ACCESS FOR ADOLESCENTS WITH DISABILITIES}

Although the number of federal and state-based initiatives targeted on adolescents has increased since passage of PL 94-142 in the mid 1970s, there is limited evidence prior to that time that adolescents with disabilities were considered capable of benefiting from traditional schooling, gaining competitive employment, or becoming valued citizens in the community (Sitlington, Clark, \& Kolstoe, 2000). Fortunately, initiatives in the areas of career education of exceptional youth (e.g., Brolin \& Kokaska, 1979; Kokaska \& Brolin, 1985) have targeted the design of programs that would enable students to acquire an array of competencies in the areas of daily living skills, personal-social skills, and occupational guidance and preparation skills. In addition, in 1978, the Office of Special Education Programs funded five research institutes to study problems in the area of learning disabilities. One of these institutes (the Institute for Research in Learning Disabilities at the University of Kansas) had as its sole research focus the study of adolescents with learning disabilities. This was a significant investment (several million dollars), but the funding ended after 5 years.

In the mid-1980s, Madeline Will, director of the Office of Special Education and Rehabilitative Services, championed the transition movement that extended career education issues into the realm of transition programs and services and linkages with adult community services. The majority of state and federally supported initiatives that related to adolescents with disabilities were aimed at addressing issues and developing programs surrounding transition (e.g., transition assessment, transition to employment, job placement, transition to postsecondary education, transition to adult independent living); however, meager resources were directed to supporting efforts to design and validate academically based interventions to enable adolescents with disabilities to successfully respond to rigorous curricular demands leading to high school graduation.

Consequently, the country's relatively low priority for creating interventions that would enable adolescents with disabilities to gain access to and also succeed within an inclusive academic environment in high school settings has resulted in a largely unfavorable situation for these older students. As a result, American high schools, by and large, have failed to prepare adolescents with disabilities to obtain a standard diploma and also have fallen short in preparing them to face the demanding expectations of the globalization of commerce and industry, the dramatic growth of technology, and the dramatic transformation of the workplace and the very nature of work itself (Martin, 1999; Oliver, 1999; Rifkin, 1995).

As discouraging as the above state of circumstances may seem, a host of emerging trends may exacerbate the situation 
even further for adolescents with disabilities. Foremost among these trends are:

1. The increased expectation that all learners, including those with disabilities, meet the curriculum standards adopted by states and professional organizations (Thurlow, Elliot, \& Ysseldyke, 2003; National Research Council, 1997);

2. The pressure to include adolescents with disabilities in the general education classroom for as much of the school day as possible (Wagner et al., 1993);

3. The explosion of knowledge and information and the growing expectation that all students not merely acquire but also integrate thinking skills with their content-area knowledge in authentic problem-solving activities (Kameenui \& Carnine, 1998); and

4. The clear expectations set forth in PL 105-17 that programming for students with disabilities be outcome-based within the context of successfully mastering the general education curriculum (Turnbull, Rainbolt, \& Buchele-Ash, 1997).

\section{A RENEWED COMMITMENT TO MEANINGFUL ACADEMIC ACCESS}

Under the leadership of Drs. Louis Danielson (Director of the Research to Practice Branch of the Office of Special Education Programs [OSEP]) and Bonnie Jones (Project Officer for Secondary and Transition Programs, OSEP), a growing set of federal investments have been made in initiatives designed to increase the array of research-based interventions available to practitioners who work with adolescents with disabilities for the purpose of enabling them to graduate from high school with a standard diploma. One of the major OSEP investments to this end was the creation of the Institute for Academic Access (IAA), a 5-year collaborative research project between researchers at the University of Kansas Center for Research on Learning (CRL) and the University of Oregon.

In the broadest sense, the purpose of the IAA is to determine ways to substantially improve educational outcomes for adolescents with disabilities who can be educated within the general education curriculum by conducting a highimpact program of research that takes into account the unique characteristics presented by these students and the complex dynamics that define the setting and circumstances unique to secondary curricula and schools. Together, special and general educators are seeking to redefine what they do in order to achieve results for students with disabilities that are consistent with the demands of standards-based reforms (National Research Council, 1997).
Three major goals guide the work of the IAA. First, investigators are synthesizing current knowledge in four areas:

1. Instructional planning for academically diverse classrooms;

2. Evidence-based instructional practices that can be used in challenging core classes;

3. Instructional technology, media, and materials; and

4. Contextual factors that influence learning in high schools.

Critical gaps in current knowledge are identified to guide IAA work.

Second, IAA partners conduct a rigorous program of research to:

1. Supply secondary educators with a menu of validated interventions from which they can build instructional programs that fit their courses and schools;

2. Make available high-quality teacher training programs to promote implementation of research-based practices and coordination of instruction; and

3. Provide educators with methods for working together, creating effective contexts for learning, and delivering combinations of interventions.

Third, Institute partners are designing, implementing, and evaluating a dissemination approach that will result in widespread use of the products of the IAA in high schools across the nation. In short, the IAA is attempting to generate timely and critical information on effective strategies for enabling adolescents with disabilities to benefit from the general education curriculum in high schools.

\section{CONCEPTUAL FRAMEWORK FOR THE IAA}

The conceptual framework for promoting the success of adolescents with disabilities in the core academic curriculum of secondary schools has been designed in conjunction with critical stakeholders (e.g., educators, parents, students). This framework represents a departure from instructional practices traditionally used in secondary schools. Typically, these programs are fragmented, consist mainly of tutoring activities (Mercer, Lane, Jordan, Allsop, \& Eisele, 1996) and an occasional accommodation (Lancaster \& Gildroy, 1999), and are oriented toward getting the student through assignments in basic required courses.

In contrast, the conceptual framework for this project represents an optimistic vision of what these students can accomplish and how they can accomplish it. The vision has grown out of a rich tradition of nearly 25 years of research conducted at the Universities of Kansas and Oregon in the 
area of disabilities (e.g., Bulgren, \& Lenz, 1996; Grossen \& Carnine, 1996; Kameenui \& Carnine, 1998; Schumaker \& Deshler, 1992). It embodies a different approach to instruction for the majority of adolescents with disabilities who are enrolled in the general education curriculum. Within this vision, students can meet academic standards in the core curriculum and become prepared for future education/training. The approach is founded on the contention that adolescents with disabilities have the greatest probability of being successful both in secondary school and beyond if they acquire critical knowledge that relates to their lives and can learn how to acquire additional knowledge through carefully structured practice opportunities.

The conceptual framework shown in Figure 1 specifies three major components being developed and validated, each of which contains several interventions. Collectively, these interventions eventually will provide educators with a menu of validated practices from which they can choose and through which they can build core academic courses and academic programs tailored specially to their students and schools.
Some of the interventions are being developed "from scratch" and validated through the IAA. Other interventions already have been validated as effective in improving the performance of middle school students with disabilities (e.g., Carnine, 1997; Engelmann \& Carnine, 1988) and must be validated as effective for high school students. Still others to be included have already been validated in experimental studies as effective with high school students with disabilities in limited subject areas (e.g., Bulgren, Schumaker, \& Deshler, 1994; Lenz, Alley, \& Schumaker, 1987) but have yet to be validated in other subject areas and in combination with other interventions. The best ways of preparing teachers to use combinations of these interventions are being identified, and the structures and contexts within which they can be best combined and delivered are being developed.

The first intervention component in the conceptual framework illustrated in Figure 1 is Planning. Within this component are methods that teachers use to plan and structure core subject area courses so all students can succeed

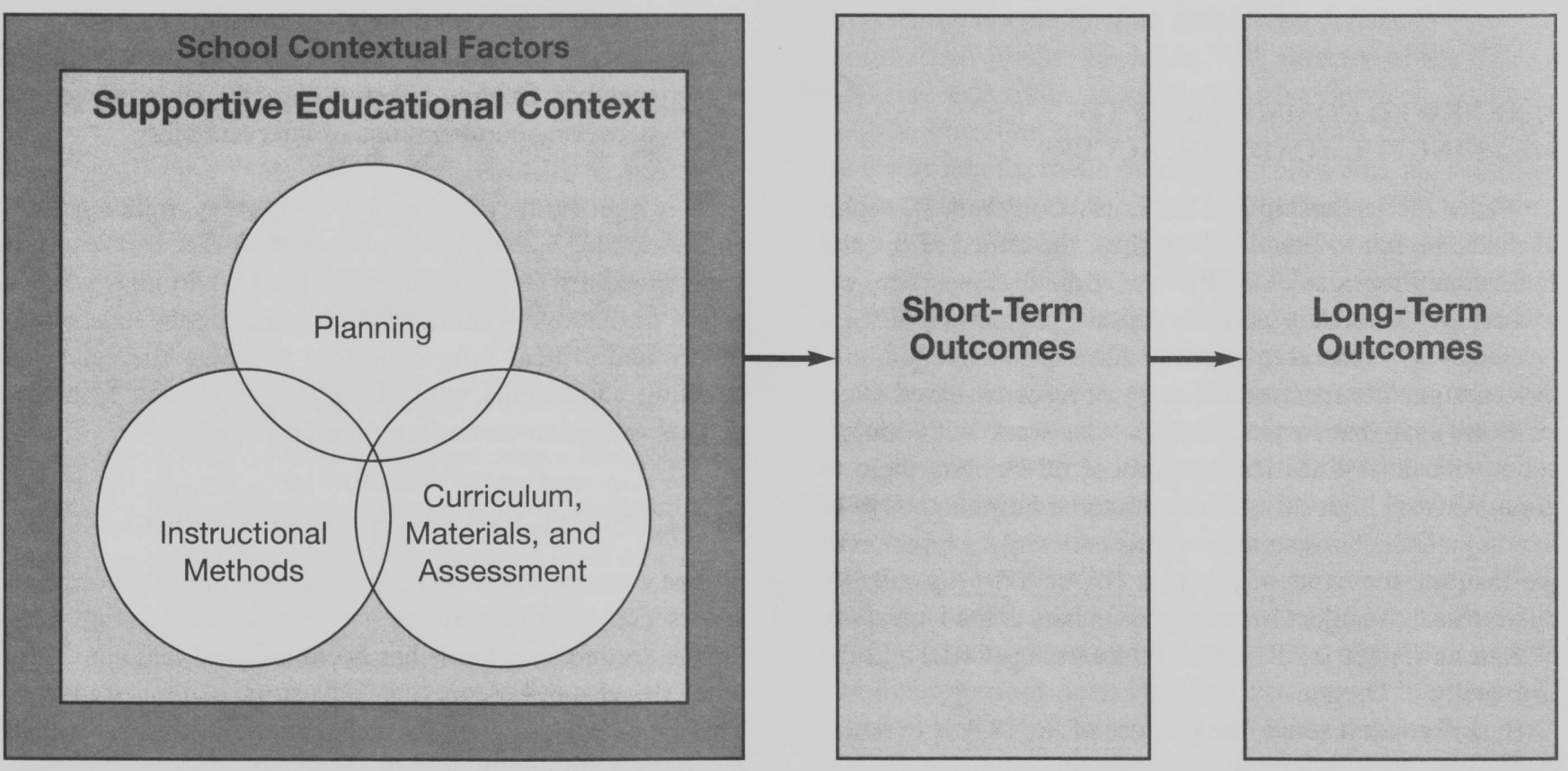

Short-Term: Attainment of standards, improved understanding, improved retention, average or above test grades, average or above course grades, improved short-term goals, improved hope, improved self-esteem

Long-Term: Completion of sequence of required courses, high school graduation lifelong learning skills, enrollment in postsecondary education 
and attain required standards. Within the IAA, teachers and researchers are working together to create two types of planning methods:

1. Methods that enable them to match content to the standards their students are expected to meet, and to select or create materials, activities, assignments, and instructional methods that will help them instruct their students to meet these standards; and

2. Methods that enable IEP teams to work together to create IEPs for students with disabilities in relation to the required academic standards (e.g., state assessment standards).

The Instructional Methods component focuses on instructional methods that teachers can use in core required courses to ensure that students understand and retain the content. This component is founded on research-validated instructional principles (Carnine, 1995, 1997; Carnine, Engelmann, Hofmeister, \& Kelly, 1987; Darch \& Carnine, 1986; Darch, Carnine, \& Kameenui, 1986; Kelly, Gersten, \& Carnine, 1990), as well as extensive lines of programmatic research conducted through the auspices of both partner research sites.

This conceptual framework involves the general education teacher in the role of an expert learner who teaches, models, and guides students in acquiring the processes involved in learning content as well as the content itself through the use of teaching routines. Thus, interventions are being created for the Instructional Methods component that combine available teaching routines and other routines identified as needed by high school teachers and researchers with what is known about strategic instruction.

The third component of the framework is Curriculum Materials and Assessment. It is composed of learnerfriendly materials (e.g., textbooks, videodisc programs, multimedia systems, graphic devices) that high school general education teachers can use, along with the instructional methods described above, to present content to their students. It also focuses on tools that can be practically and effectively used to assess students' progress toward attaining the standards and to report progress to students and parents.

Though many teachers focus on the nature of an instructional material (e.g., textbook versus computer discs), the critical dimension of quality in an instructional tool is not so much the delivery medium as the way instruction is designed. Thus, these materials are based on six design principles formulated by researchers at the University of Oregon, including elements such as big ideas, conspicuous strategies, mediated scaffolding, planned review, and so on.

The three instructional components illustrated in Figure 1 work together in a synergistic fashion to create a critical mass of interventions that are sufficiently powerful to impact the performance of students on rigorous academic tasks. In addition, they function within a supportive educational context, one in which teachers receive the necessary support from administrators, special educators, and other support staff to enable them to teach within the new instructional paradigm. This supportive educational context, in turn, functions within the larger context of a school reform structure in which the continuous learning and professional development of the teaching staff is valued and promoted through ongoing dialogue, planning, and activities in which parents, students and other members of the community are involved along with school staff.

\section{UNDERSTANDING THE REALITIES OF THE HIGH SCHOOL CONTEXT}

As depicted in Figure 1, interventions must be implemented within the realities and constraints of the high school setting. Hence, the first phase of IAA work has been to do a careful analysis of an array of high school settings to determine the nature of demands that adolescents with disabilities are expected to meet if they are to be successful within inclusive general education classrooms, as well as to understand the actual extent to which students with disabilities currently have access to and are succeeding in rigorous general education classes.

The purpose of this research was to study nine high schools representing geographic, demographic, and organizational diversity, to measure a broad array of instructional and contextual variables, and to identify contextual features that support or hinder the use of validated practices by teachers and the learning of adolescents with disabilities. The major findings and conclusions from this phase of IAA research are summarized here.

\section{DETAILS OF THE DESCRIPTIVE STUDY}

\section{The School Settings}

Nine public high schools serving grades 9 through 12 participated. Three types of high schools participated.

1. Three represented schools, referred to as "urban high schools," located in high-density areas (i.e., urban/metropolitan areas populated by more than 150,000 people) and in which more than $50 \%$ of the student population consists of "students living in poverty," defined as students who had applied for and received free or reduced-price lunch benefits.

2. Three of the high schools, referred to as "rural high schools," were schools located in low-density population areas (i.e., towns of fewer than 10,000 people, and fewer than 150 people per square mile) and in 
which more than $10 \%$ of the student population consisted of students living in poverty.

3. Three of the high schools, referred to as "suburban high schools," were located in towns having a population of more than 45,000 people and fewer than 150,000 people and in which fewer than $10 \%$ of the student population was composed of students living in poverty.

Three of the high schools (one urban, one rural, and one suburban) were located in Kansas. Three of the high schools (one urban, one rural, and one suburban) were located in the state of Washington. Two schools (one rural, one urban) were located in California. One school (suburban) was located in Oregon. The student populations in the urban schools ranged in size from 1,031 to 3,508 students. In the rural schools, the populations ranged in size from 330 to 693 students. The student populations in the suburban schools ranged in size from 931 to 1,691 students.

The percentage of students with disabilities in the nine schools ranged from $3.9 \%$ in a suburban school to $14.8 \%$ in an urban school. Six of the schools had Caucasian majorities, ranging from $67 \%$ to $95 \%$ of the student population. One school had a Latino/Hispanic majority; one school had an African-American majority; and one had an Armenian majority.

Within these high schools, students were observed in three settings:

1. The special education class setting, defined as any classroom or space in which an adolescent with disabilities was receiving services to assist him or her to succeed in general education courses.

2. General education classrooms, in which rigorous ninth-grade general education courses were being taught. A rigorous general education course, defined as a math, English, social studies/history, science, or foreign language course that a student must pass to earn a standard high school diploma, that contributes credits toward a standard high school diploma (as in the case of a foreign language course), that has been designed for helping students meet state standards, and that was being taught by a teacher with credentials in the subject area. The specific rigorous courses targeted for this investigation were five courses typically taught to ninth graders: algebra I, ninth-grade English, biology, history, and Spanish I.

3. Some students also were observed in settings before and after classes, such as the hallways, lunch rooms, and school-entry areas. Teachers were observed both in special education classrooms and in general education classrooms.

\section{The Participants}

\section{Students}

The students with disabilities (SWDs) targeted in this project were students who had been formally classified as having a disability (e.g., a learning disability, emotional disorder/disturbance, behavioral disorder, physical disability, visual disability, hearing disability, or other health impairment) according to state guidelines. In addition, they were students who either had been enrolled in one or more rigorous general education course as defined above or were judged by their special education teachers as students who could have been enrolled in one or more rigorous general education courses successfully if they had had the appropriate instructional support.

These were students who were expected to earn standard high school diplomas by their special education teachers. Hereafter, this will be the only type of student with disabilities referred to in this report. In general education classes where no SWDs were enrolled, they were replaced in the study by "at-risk students." "At-risk (AR) students" were those who had each earned more than one failing grade in a required course in a previous semester or who already were failing at least one rigorous general education course as defined above at the time of the study. In addition, they were students who had not been formally classified as having a disability.

A third group of participating students were normally achieving (NA) students. These were students who were enrolled in the same ninth-grade English classes as participating students with disabilities and who were earning at least a "C" grade in the course. They were matched to the students with disabilities by gender and grade level.

\section{Parents}

Participating parents were those who had agreed to allow their sons or daughters to participate in the investigation.

\section{Teachers}

Participating general education teachers were those who were teaching the targeted general education courses (algebra I, English, history, biology, Spanish I) to heterogeneous classes of students, including students with disabilities and/or at-risk students. These teachers were certified to teach their subject area (e.g., certified to teach algebra). The special education teachers were teachers who were providing special education services to students with disabilities.

\section{School Administrators}

The principal of each school participated. An individual who had been designated as the person responsible for administering the special education program in the school 
and who had an office/classroom in the school participated as the special education administrator.

\section{The Measurement Tools}

A broad array of measurement tools and instruments was designed to help to gather the data needed to answer the major questions. Each instrument is described briefly in the following paragraphs. This description is intended to enhance an understanding of the findings from this comprehensive study of key contextual factors in high school settings and to provide a perspective on the breadth and depth of variables considered.

\section{Student Instruments}

Adolescents in the study were asked to complete three forms. On the first form, called the Student Survey, students indicated, using a 7-point Likert-type scale, how much they agreed or disagreed with each of 37 items. The items related to their attitudes about learning (e.g., "I don't want to do the hard work in a challenging class"); academic skills (e.g., "For the things that I am asked to do in my high school classes, I feel that I have good skills to be successful"); beliefs (e.g., "I believe I can get better as a learner"); and relationships with adults and students in the school (e.g., "I have a close relationship with at least one adult in this school").

On the second form, called the Student Satisfaction Form, students rated their satisfaction using a 7-point Likerttype scale for each item, with " 1 " indicating that they were "Completely Dissatisfied" and "7" indicating that they were "Completely Satisfied." Two forms of this questionnaire were used, one for SWDs and one for normally achieving students.

The items on the Student Satisfaction Form for SWDs related to their satisfaction with how their special education teachers help them succeed in general education classes, how their special education teachers and parents communicate, how their special education teachers are preparing them for life after high school graduation, how the teachers of their required academic courses help them learn, their comfort with and outcomes associated with those academic courses, and their overall high school experience. They also were asked to list three skills they have learned in high school that have been useful in their succeeding in required courses, and three skills they need to learn to get better grades in required courses.

The items on the Student Satisfaction Form for normally achieving students were the same as the items on the Satisfaction Form for SWDs except the wording was changed slightly. For example, the SWDs were asked to indicate how satisfied they were with how the special education teacher was helping them complete assignments for required courses, whereas the normally achieving students were asked to indicate how satisfied they were with how the teachers of their required academic classes were helping them complete assignments for required courses.

The third form, called the Student Demographics Form, was used to gather personal information about the participating students. This included items such as their age, race, sex, and whether they receive free or reduced-price lunches at school.

SWDs were administered two tests. The Multilevel Academic Survey Test (MAST) was given to provide a standard measure of student achievement across students in the different participating schools. This test yields achievement scores in reading and math. Percentile scores and grade-level achievement scores were utilized to describe the students.

In addition, the vocabulary subtest of the WAIS-III (or the WISC-R, as appropriate for age) was administered to obtain a measure of student ability across students in each school.

Further, the students were observed using three observation systems. First, SWDs were observed in their special education classes using the Student Support Class Observation System, a time-sample recording system consisting of a recording sheet and a behavioral code. The observer recorded the student's behavior and other factors associated with the ongoing instruction during 10-second intervals. Specifically, in the first column, the observer recorded the target student's behavior using a few words or a phrase. In the remaining columns, the observer placed tallies indicating whether a given behavior was instructional or noninstructional, whether the instruction during that interval was research-based, the type of academic response the student made, the instructional approach used with the student, the materials the student was using, the instructional grouping in which the student was included, and the sensory modalities the student was using. The observer also noted the number of students and teachers with whom the student was interacting during the interval.

Second, SWDs (or at-risk students, if no students with disabilities were enrolled in a given class) were observed in rigorous general education classes using the Student General Education Class Observation System. This system was similar to the observation system used in special education settings to observe students.

Third, SWDs and normally achieving students were observed throughout a whole school day using the Case Study Observational System. This system was composed of three observation forms. The Class Observation Form was used to record the student's behavior in relation to class activities, the number of contacts the student had with the teacher and other students, the number of minutes that elapsed before the student began work after the class period 
began, the student's mood/demeanor, the student's seat location, accommodations made for the student, and the homework assignment. This form was used in every class in which the student was enrolled and which the student attended during the day he or she was scheduled to be observed (some of the schools used block scheduling, so some of the students did not attend all the classes in which they were enrolled on the day they were observed).

The Non-Class Observation Form was used to observe the student before school, between classes, during lunch, and after school while on school grounds. Again, the student's demeanor and behavior, as well as the contacts made with teachers and students, were recorded.

In all the students' classes, the Class Description Form, which contained eight open-ended items, was used. The observer used this form to report, in sentence form, what had transpired during the class period. For example, the first item asked the observer to provide a general description of the lesson, the fourth item asked the observer to describe the relationship between the target student and other students, and the sixth item asked the observer to describe the general outcome of the class for the target student.

The students who were followed for a whole school day were also interviewed. The Interview Protocol included 13 open-ended questions that were asked orally of all the participating students individually. The students' oral responses were tape-recorded. In general, the questions focused on the student's reaction to the school day. For example, the students were asked to explain how the day had been typical or unusual, the best thing that had happened during the day, the discouraging things that had happened during the day, and what they planned to do after school.

In addition, the same students were asked to discuss, in small focus groups, their answers to oral questions. Participating students with disabilities in a school were grouped together, and participating normally achieving students in a school were grouped together for these discussions. The Student Focus Group Protocols contained 12 questions for the students with disabilities and 11 questions for the normally achieving students. The only difference between the two protocols was that the students with disabilities were asked the question, "In light of the fact that you have a disability, how difficult is it to be successful in this school?" and the normally achieving students were not. Other questions related to topics such as the workload they were carrying, their biggest worries about school, the helpfulness of the teachers, and barriers to their success in school.

Finally, information related to the participating students was gathered from school records using a form called the Student Information Form. Two versions of the form were created, one for the SWDs and one for the normally achieving students. The form was used to gather standardized test scores, the names of classes in which the student was enrolled, the semester grades the student earned, the number of days the student was absent, suspended, or expelled, the number of disciplinary actions incurred during each year of high school, and scores on state competency exams. The only difference between the version for the SWDs and the normally achieving students was that there was a place on the version for the SWDs to record the scores earned on individually administered achievement and aptitude tests and information about the student's disabilities.

\section{Parent Instruments}

Parents completed the Parent Satisfaction Form. Two forms of this questionnaire were used: one for parents of students with disabilities and one for parents of normally achieving students. The two forms were parallel, consisting of 56 items each. With the exception of a few differences in wording, the items on both were similar. Items were grouped in eight major sections relating to factors such as the parents' satisfaction with their relationship with school personnel, the ways teachers were helping their children succeed in high school, the ways teachers were helping their children prepare for life after high school, and their children's enrollment in required classes. For the large majority of the items, the parents were asked to rate their satisfaction on a 7-point Likert-type scale ranging from "1" (Completely Dissatisfied) to "7" (Completely Satisfied).

Parents also participated in focus groups. The Parent Focus Group Protocol posed five open-ended questions to a small group of parents. The parents each were asked to respond to and discuss their answers to these five questions:

What do you consider to be the greatest challenge that your son/daughter faces in being successful in high school?

What do you expect your son/daughter to receive as a result of his/her high school education?

What are your expectations for the nature of special education services provided to your son/daughter in high school?

What skills and strategies does your son/daughter most need?

What guidance would you give us as we design interventions?

The parents' responses were audiotape-recorded. After the session, their responses were written verbatim in sentence form.

\section{Special Education Teacher Instruments}

Special educators completed four forms. The purpose of the Special Education Teacher Information Form was to 
gather personal information about the teachers. The form contained 27 items that focused on information such as the teacher's age, race, sex, educational history, teaching certifications, and history as a teacher.

The Special Education Teacher Questionnaire gathered information about the teachers' perceptions of their roles as special educators, how they spend their time at school, how they make decisions about how students will be enrolled in courses, their beliefs about what the students need in order to succeed in rigorous courses, barriers to students' success, and the types of training they believed they need to help students succeed. Some of the questions asked the teachers to rank the items in a list of items indicating the most important. Other questions asked the teachers to specify the percentage of time or the number of hours per week they engaged in a certain activity.

The Types of Classes Form gathered information about the types of classes in which the students with disabilities were enrolled. The form consisted of five pages, each corresponding to a different type of class: (a) classes taken for general education credit that were taught by a special educator (Type A); (b) classes taken for general education credit in which only low-achieving students and students with disabilities were enrolled, which were taught by a general education teacher (Type B); (c) rigorous general education classes that were taught by a general education teacher and in which a heterogeneous population of students was enrolled (Type C); advanced placement classes (Type D); and other classes (e.g., electives such as physical education, art, band) (Type E). On each page were spaces for the teacher to specify the name of the course, name of the teacher teaching the course, and number of students with disabilities enrolled in the course.

The Special Education Teacher Satisfaction Form, the third form that special education teachers completed, gathered their satisfaction with the educational program for SWDs in their school, its outcomes, and their own performance as teachers. The questionnaire had 47 items formatted with a 7-point Likert-type scale ranging from "1" (Completely Dissatisfied) to "7" (Completely Satisfied). The items were organized into the following sections: those pertaining to how the general education teachers work with the special educator; those pertaining to the instruction provided to the SWDs by the general education teachers, those pertaining to progress reports created by general educators and shared with the special educator; those pertaining to student outcomes; those pertaining to professional development experiences in which the special educator had participated; and those pertaining to the special educator's own assessment of his or her performance with regard to ensuring SWDs' success (grades of "C" or above) in general education classes.
In addition to completing the three forms, the special education teachers were observed teaching in their classes, using the Special Education Teacher Observation System. This system was a time-sample recording system consisting of a recording sheet and a behavioral code. The recording sheet was used to record the teacher's behavior and other factors associated with the instruction taking place during 10 -second intervals. The observer noted whether a given behavior was instructional or noninstructional, whether the instruction was research-based, the type of instructional methods used, the instructional approach used, the materials the students used, and the sensory modalities the students used. The observer also indicated the number of students and teachers with whom the special education teacher was interacting during the interval.

In addition, the observers completed four forms after observing the special education teacher. On the first, the Technology Form, the observer recorded any technology that the students used at the teacher's direction during the class period being observed. The observers also noted the name of the technology that was used (e.g., the name of software) and whether there was any evidence of a research base for the technology.

On the second form, the Instructional Materials Form, the observer recorded any instructional materials the students used at the teacher's direction during the class period being observed. The observers recorded the name of the material and whether there was any research base for the material.

The third form, the Classroom Climate Checklist, contained nine items representing the type of classroom climate the teacher had created. For example, the items included whether the classroom was neatly arranged, whether the room had any motivational posters, and whether the room had any instructional posters or aids.

The fourth form, the Class Description Form, contained nine items related to what had transpired during the class period. As examples, the first item asked the observer to provide a general description of the lesson, the second item asked the observer to describe the overall atmosphere the teacher had created, and the third item asked the observer to describe the students' attitude toward learning.

\section{General Education Teacher Instruments}

General education teachers completed three instruments. The first, the General Education Teacher Information Form, was identical in format and content to the Information Form designed for the special education teachers. The General Education Teacher Satisfaction Form was similar in format and content to the Special Education Teacher Satisfaction Form, but the words were changed slightly to fit the general education focus. For example, the general education teachers were asked to indicate how satisfied they were with the 
way the special education teachers worked with them, whereas the special educators were asked to indicate how satisfied they were with the way the general education teachers worked with them.

The purpose of the General Education Teacher Questionnaire was to gather information from the teachers about a particular course that they were teaching, including information about the instructional methods and assessments being used, the students enrolled in the course, demands associated with the course, teacher beliefs, and support received by the teacher from others in the school. The survey contained 90 items.

For instance, they were asked if they used a particular instructional method, type of assessment, or accommodation or the degree to which success in their course was dependent on students having a specific skill. For other items, the teachers were asked to indicate the percentage of work time they spent on a given activity. Still other items were openended, requesting the teachers to write an answer in either phrases or sentences (e.g., "Please list the five most common adaptations/accommodations you regularly use in this course"; "Please list the activities on which you collaborate with special education staff").

In addition to completing the three forms, the general education teachers were observed teaching one class, using the General Education Teacher Observation System. This system was similar to the observation system used with the special education teachers. In columns on the recording sheet, the observer recorded the teacher's behavior and other factors associated with the instruction, during 10-second intervals. The observer noted whether a given behavior was instructional or noninstructional, the type of motivational or instructional method being used, the materials the students were using, the way the students were grouped for instruction, and the sensory modalities the students were using. The observer also indicated the number of students and teachers with whom the general education teacher interacted during the interval.

As in the special education settings, the observers completed four forms after observing the general education teacher. These forms were identical to the ones used in the special education settings. On the Technology Form, the observer recorded any technology that the students used at the general education teacher's direction during the class period being observed. On the Instructional Materials Form, the observer recorded any instructional materials the students used at the teacher's direction during the class period being observed. On the Classroom Climate Checklist, the observer recorded whether nine items that might represent the type of classroom climate the teacher had created were present or absent. On the Class Description Form, the observer recorded, in sentence form, descriptions of what had transpired during the lesson.

\section{School Administrator Instruments}

The Principal Satisfaction Form was designed to measure the principal's satisfaction with various aspects of the educational program for SWDs enrolled in general education classes. The questionnaire included 54 items, grouped into eight sets. Specifically, the principals were asked to indicate their satisfaction with how the special education teachers are working with the general education teachers, how the general education teachers who teach required courses are working with the special education teachers, how the special education teachers are helping students with disabilities succeed in required general education classes, the instruction provided by general education teachers for students with disabilities, the progress of students with disabilities in required general education classes, overall outcomes related to the education of students with disabilities, their own performance with regard to ensuring success for students with disabilities, and the professional development experiences that had been provided to teachers with regard to ensuring the success of students with disabilities in the general curriculum.

The Principal Information Form was a survey instrument containing 26 items. This form was designed to gather demographic and personal information about the principals, such as their age, race, sex, number of years in the education profession, and educational history.

The Principal Interview Protocol consisted of 68 questions grouped in seven sections. The purpose of the interview was to gather information from the principals about the ways their schools were serving students with disabilities, providing professional development experiences with regard to serving students with disabilities, and their attitudes about serving students with disabilities. The questions related to the school's organization and curriculum, programs that currently were serving students with disabilities, staff-development experiences, planning with regard to ensuring that students meet state standards, program-evaluation activities, instructional and adaptive technology available to the students with disabilities, and the school budget as it relates to serving students with disabilities and providing inservice programs for the staff.

\section{Special Education Administrator Instruments}

Three of the instruments (the Special Education Administrator Satisfaction Form, the Special Education Administrator Information Form, and the Special Education Administrator Interview Protocol) designed to gather information from the special education administrators were parallel in form and content to the instruments designed for the principals, except that the wording was changed slightly in some of the items to address the different job functions of the special education administrators. In addition, the special education 
administrators were asked to fill out the Special Education Services Form, designed to gather information about the special education services being offered in the school. Items related to the types of special education teachers and support staff working in the school, the numbers of each type of student with an exceptionality served in each general type of program (e.g., resource, self-contained), and names of the specific programs designed to support students with disabilities in rigorous general education classes.

\section{School Instruments}

Several forms were completed to collect data on the participating schools. The School Climate Form contained 16 items that an observer recorded as either present or not present in the school. Example questions included: "Are rules posted in the classrooms?" "Are there visual displays of student work?" and "Is there evidence of student academic goals posted?" The researcher filled out the form after taking a tour of the school.

The School Data Form contained places for the researchers to record information about the school, such as the number of different kinds of teachers in the school, the number of students receiving free lunches, the number of students representing different racial groups served by the school, and the number of students enrolled in the five target courses in each grade in the school. The School District Data Form contained places for researchers to record information about the school district associated with a participating school. Information included the number of schools in the district, the number of teachers employed by the district, the number of students served by the district, the staff development hours required for teachers each year, and the dropout percentage for the district.

The Municipality Data Form contained places for the researchers to record information about the town where the school was located. For example, the population of the municipality and the tax base for the municipality were collected on this form.

The State Data Form contained places for researchers to record information about the state where the participating school was located. This form was used to collect information such as the state requirements for high school graduation, total number of students enrolled in the state, and average per-pupil expenditure in the state.

\section{THE MAJOR FINDINGS}

Following is a brief synopsis of some of the findings from the descriptive study described above.*

\section{Administrator Results}

Although all of the administrators stated that they wanted to help SWDs be successful, eight of the nine high schools had no policy related to inclusion of SWDs in general education courses. Further, the same schools had no methods for evaluating the outcomes of special education programs and no plan for improving these programs. Special education administrators were not familiar with the various academic tracks in which students could be enrolled within the general education curriculum.

In addition, according to the administrators, the general educators and special educators seemed to be quite isolated from each other in seven of the nine schools. Budgets for general and special education were separate, staff development activities were separate, planning time was not coordinated in such a way that general and special educators could consult with or collaborate with each other, their roles were separated, and responsibility for educating SWDs was not shared. Furthermore, for the most part, general educators had received no or very limited instruction on how to teach SWDs.

Urban principals were much more satisfied with their staffs and the way they instruct students with disabilities than were the suburban and rural principals. All of the urban principals' mean ratings were above 5.5 and several were above 6.3 on a 7 -point scale. By contrast, many of the rural and suburban principals' ratings were in the 3- and 4-point range. When their ratings were averaged together, the principals were least satisfied with the way teachers report the progress of SWDs to them.

Overall, the ratings of the special education administrators were lower than the ratings of the principals. Although the suburban administrators were the most satisfied group, none of their mean ratings was above 5.6. Most of the mean ratings for the special education administrators fell within the 2-point, 3-point, and 4-point ranges. The administrators as a group were least satisfied with the professional development experiences that had been provided to teachers to help SWDs succeed in general education classes. The mean rating for items in this section was 2.9 on the 7-point scale.

\section{Special Education Results}

Seven of the nine schools had no designated services for providing support to SWDs enrolled in general education classes. In the two schools in which these services were available, one had a resource program in which SWDs received help with their homework and some remedial instruction in basic skills. In the other school, students received instruction in learning strategies, help with homework, and some instruction in career and life skills.

\footnotetext{
*Detailed research reports are available from the University of Kansas Center for Research on Learning, 518 J. R. Pearson Hall, 1122 West Campus Road, Lawrence, KS 66045; or these reports can be found online at: www.ku-crl.org
} 
These were the only two schools in which the majority of SWDs were enrolled in rigorous general education courses taught by general education teachers in which a heterogeneous population of students were enrolled (Type C classes). The exception was a special algebra class in each of these two schools in which SWDs were enrolled. Otherwise, the students were enrolled in heterogeneous classes taught by general education teachers. One of these schools was the only participating school in which a written policy related to inclusion was in place.

In the other schools, SWDs either were enrolled in subject-area courses specially designed for special education students taught by a special education teacher (five of the schools) or were enrolled in subject-area courses specially designed for at-risk and special education students taught by a general education teacher or by a general educator teaming with a special educator. In courses taught solely by a special educator, students in several grades were often present in the classroom at the same time. Students worked independently on assignments and frequently were observed working on and asking the teacher for help on other assignments unrelated to the title of the course (e.g., working on math assignments when they were in English class). Thus, the roles of the special education teachers varied according to the types of classes they were teaching. In most of the schools, these teachers were teaching subject-area courses. The role of teaching the students skills and strategies was limited to only a few teachers in a few schools.

In response to questions on the survey, the special education teachers indicated that their most important roles with regard to supporting students in general education courses were teaching the students learning strategies and consulting with general education teachers. Before enrolling students in a general education course, they reported that they consider the general education teacher's attitude about teaching SWDs first, and the teacher's instructional methods second.

Results of the special education class observations showed that teachers and students were engaged in instruction for varying amounts of time in these classes across the schools. In one school, the teachers were engaged in instructing the students as much as $72 \%$ of the class time, but in most schools, they engaged in teaching the students about half of the time. In addition, they interacted with the students about half of the time. The percentage of time students spent in instruction ranged from $39 \%$ to $91 \%$, depending on the school. Not surprisingly, the more time teachers spent in instruction, the more time students were engaged in instructional activities.

When they were instructing, special education teachers spent most of the time talking to students by either lecturing or giving directions. They also spent time monitoring students (watching students as they worked). They rarely used instructional methods that have been validated for teaching students with disabilities such as modeling, verbal rehearsal, and elaborated feedback. In only one school did teachers use research-based instructional programs, and those were the teachers who were teaching learning strategies. The teachers used few motivational behaviors during instruction, occasionally specifying expectations and giving brief feedback ("Good").

Overall, the special education teachers provided relatively low satisfaction ratings related to various aspects of their jobs, with many mean ratings falling in the " 4 " range on a 7-point scale. The teachers expressed the lowest satisfaction with the professional development experiences they had received in supporting SWDs in general education classes and the outcomes they were achieving in supporting these students in general education classes. Mean satisfaction ratings varied widely across the schools, with no clear pattern as to location of the school.

\section{General Education Results}

In filling out the General Education Teacher Survey, 70 high school teachers indicated that they frequently adapt curriculum and provide accommodations to improve the learning of SWDs. They also indicated that the teaching of strategies related to "how to learn" was of equal importance to teaching content. The teachers reported that smaller class sizes, more collaboration and communication with special education staff, and more competent staff are changes needed to help SWDs meet standards. On average, these teachers reported spending between 12 and 24 minutes per week in collaboration with special education teachers. Of interest is that general education teachers indicated that they believe SWDs are more likely to be successful in life than are students without disabilities who are low-achieving.

Relative to factors that general education teachers believe are contributors to academic failure for students with and without disabilities, teachers gave the highest rankings to youth goals/attitudes and youth skills/abilities. They indicated that they believe schoolwide structures and policies as well as instructional methods contribute least to academic failure. They also indicated that they believe student progress is satisfactory when about $50 \%$ of the students are mastering at least $50 \%$ of the content.

Through their written comments, the general education teachers indicated that they did not have an accurate idea of how many of their students have disabilities or which students have disabilities. Even when they did know, they indicated that they rarely knew the nature of the disability. They reported that sometimes they learned of the disability so late in the school year that they could do little to help the student succeed in the class at that point. 
When general education teachers were observed, they engaged in instruction a mean of 59\%-89\% of the intervals observed, depending on the school. For the largest portion of these intervals, they were addressing the whole group of students. They were involved in interacting with students for a mean of $70 \%$ to $95 \%$ of the intervals, again depending on the school. Spanish teachers were the most involved in instruction, for a mean of $84 \%$ of the intervals, and they interacted the most with students, for a mean of $94 \%$ of the intervals. The teachers spent the largest portion of instructional time engaged in lecture or reading aloud to studentsin some schools for an average of as many as $94 \%$ of the instructional intervals.

Other frequently observed teacher activities were giving directions, asking questions, and monitoring students as they worked. They engaged in few motivational behaviors. They also engaged in few, if any, research-based instructional methods. Math teachers used some modeling. They utilized few, if any, accommodations. None of the teachers used Content Enhancement Routines (Schumaker, Deshler, \& McKnight, 2002), validated instructional methods for enhancing learning of all students (including those with disabilities) in subject-area classes. None of the teachers used technology-enhanced instruction.

When SWDs (or at-risk students, if no SWDs were enrolled) were observed, they engaged in instructional activities for a mean of $47 \%-72 \%$ of the intervals in general education classes. The amount of time they were engaged in instructional activities did not necessarily match the amount of time their teachers were engaged in the instruction. When the SWDs were engaged in an instructional activity (in most of the schools, more than $50 \%$ of the time), they spent the largest portion of time listening. They were expected to participate in whole-class activities for a mean of between $40 \%$ and $80 \%$ of the intervals. In addition, they were expected to be working independently some of the time in most of the classes (13\%-25\%). In some subject areas, small-group activities were in use for a mean of as many as $25 \%$ of the intervals.

\section{Materials Results}

The instructional materials used in ninth-grade general education courses in which SWDs were enrolled were examined. The courses included English/language arts, biology, history, algebra, and Spanish. The texts incorporated $50 \%$ to $60 \%$ of the features of considerate text. The readability of the texts ranged from five to seven grade levels higher than the reading levels of the students with disabilities taking the courses.

Across the schools, students were observed using the same types of materials in their courses, but the amount of time the students spent using the various materials varied widely across the schools. For example, the mean percentage of intervals during which students were referring to visual aids and textbooks ranged from a low of $2 \%$ to a high of $50 \%$. The use of teacher-made materials (e.g., handouts, assignment sheets) ranged widely, from $0 \%$ in a couple of schools to $47 \%$ in another. In all of the schools, students were using basic materials such as pencils and paper at least $30 \%$ of the time. In none of the schools were students using computers or research-based materials.

In special education courses, the types of materials being used were somewhat similar across the schools, but as with the materials used in general education courses, the relative amount of time each type of material was used varied widely. In most of the schools, students were using basic materials, textbooks, and worksheets. In only two schools were the students using computers. In one of those schools, computers were used a mean of less than $1 \%$ of the intervals. In only one school were research-based materials in use for $5.7 \%$ of the intervals observed.

\section{Student Results}

The SWDs in this study were markedly different from students in the NA/AR group in terms of gender, ethnicity, and poverty. Surprisingly, they were relatively similar on measures of reading and math achievement. Specifically, $61 \%$ of the SWDs were males versus $47 \%$ males in the NA/AR group. For the SWD group, $22.12 \%$ were Hispanic/Latino and $13.3 \%$ were African-American. In the NA/AR group, only $9.5 \%$ were African-American and $1 \%$ were Hispanic/Latino. Reports on free and reduced lunch programs for SWDs indicated that $19 \%$ received free lunches (versus $3.5 \%$ for NA/ARs) and $6 \%$ received reduced lunch prices (versus $3.5 \%$ for NA/ARs).

On the Multilevel Academic Survey Test (MAST), the raw scores for reading were 29.3 for the SWDs versus 33.5 for the NA/ARs. Their mean math raw scores were nearly identical (12.2 for SWDs versus 13.2 for NA/ARs). On a measure of ability as indicated by the WISC III Vocabulary Subtest, the mean standard score for the SWD sample was 8 .

Searches of records revealed that a very small percentage of the SWDs participate in rigorous general education classes taught by a general education teacher and in which a heterogeneous population of students is enrolled (Type C classes). Specifically, SWDs were enrolled in only about 5\% of the potential core classes in which they could be enrolled. For example, for a sample of 153 SWDs in an urban high school (assuming that each student could be enrolled in four core courses), there would be a potential of 612 rigorous course enrollments $[153 \times 4=612])$. In this school, the actual number of rigorous general education enrollments was 8 . In a suburban school, with 296 total possible enrollments for 74 students, only one actual enrollment was 
recorded. In short, SWDs are overwhelmingly enrolled classes taught by special education teachers or classes taken for credit in which only low-achieving students and students with disabilities are enrolled.

SWDs performed considerably poorer than their NA/AR counterparts in their coursework, as reflected by grade-point averages (GPAs). Specifically, in core courses, $56 \%$ of the SWDs achieved GPAs of D or F and 39\% received GPAs of C. Thus, even though the majority of students are not enrolled in rigorous general education courses, they still are doing poorly in the courses in which they are enrolled. In contrast, only $18 \%$ of the NA/AR group received GPAs of D or $\mathrm{F}$, and $49 \%$ received GPAs of $\mathrm{C}$.

On state assessments or national tests (e.g., the MAT or the ITBS), SWDs performed more poorly than NA/AR students. For example, the percentage of SWDs receiving a score at or below the 20th percentile for reading achievement ranged from $86 \%$ to $100 \%$ across the schools. For math achievement, between $68 \%$ and $100 \%$ of SWDs scored at or below the 20th percentile, and for written expression, all of the SWDs scored at or below the 20th percentile. In contrast, the percentage of the NA/AR students scoring at or below the 20th percentile was less than half of the percentage of SWDs scoring at or below that level in each school.

Finally, on the Student Survey there were no discernable differences between the two groups on measures related to attitudes about learning, self-assessments about skills required to do well in school, and relationships with adults.

When SWDs were asked questions about how satisfied they were with their high school academic experiences and supports, most ratings were in the 4.5-5.5 range on a 7.0 scale (with 7.0 being completely satisfied). SWDs attending the suburban schools were generally more satisfied than students attending rural and urban schools. SWDs attending the suburban school where learning strategies were being taught were the most satisfied group. In fact, their mean ratings were above the 6.0 level (the "Satisfied" level) in all of the sections of the questionnaire except one. The level of satisfaction reported by the NA/AR students was comparable to the SWDs' ratings across the schools.

On this same survey, students were asked to report on the most useful skills they have learned in high school. Each group rated English/language arts as the most useful and mathematics concepts as the second most useful. The groups also were similar in the degree to which they endorsed the usefulness of typing and computer skills. Interestingly, however, the groups were quite different in their rating of the perceived usefulness of study skills, note taking, and life skills. In all cases, the NA/AR students rated these skills as more useful than did the SWDs. This finding may be related to what was found in the special education observation study, which indicated a lack of instructional emphasis in these areas.

\section{Parent Results}

In general, regarding communication and efficiency within the infrastructure of schools, parents reported that their students' school was not as responsive to the needs of SWDs as the parents would like. The parents cited little coordination or cooperation among special and general education teachers, exemplified by little awareness of students' Individualized Education Programs on the part of general education teachers. In addition, some parents noted lack of overall efficiency in assigning students to classes or correcting incorrect assignments to classes, frequent class-time interruptions, and interruptions in the flow of instruction caused by changes in the classroom such as the use of student teachers.

Regarding responses to students with disabilities in the general education classroom, parents reported that few adaptations or accommodations were made to help their students in general education classes, that they often were ignored or considered lazy, and that students were less likely to ask questions in general education classes than special education classes for fear of being embarrassed.

Regarding parental hopes and expectations for their students, parents mentioned that they wanted their students to leave school with social competence and the academic skills that would allow them to function in future educational or employment settings. In terms of social competence, parents specifically mentioned that they hoped their children would learn self-advocacy skills, become self-motivated, and have positive peer associations. Relative to their children's futures, parents wanted their students to get a diploma, to learn practical life skills including computer training, and ultimately to be employed in a good job.

Regarding responses that schools could make to enhance the educational results for their students, parent suggestions included the following:

- Special education teachers should provide more help for their students.

- Students should be taught how to learn through learning skills and strategies, with special emphasis on reading and notetaking.

- Instruction in these skills and strategies should be incorporated into general education classes.

- Most important, these skills and strategies should be taught earlier than the high school years.

Two interesting items of feedback were that parents attached value to self-contained special education classes for difficult required subject-area courses, and they did not always appreciate that teachers expressed to students what the parents perceived to be unrealistic expectations that the students would and should go to college. 
When parents were asked to indicate how satisfied they were with various facets of their children's educational program, many of the parents' ratings were low. In fact, only one mean rating for one section of the parent questionnaire reached the 6.0 ("Satisfied") level, and that was for parents of students enrolled in Suburban School \#3 when they rated their relationship with school staff. Parents of students enrolled in that school were the most satisfied overall. Most of the other mean ratings by parents whose children were enrolled in the other suburban and the rural schools were in the 2-point, 3-point, and 4-point ranges. Overall, parents of students in the urban schools were the most satisfied group, with most of their mean ratings in the 5-point range.

\section{SIGNIFICANCE OF THE FINDINGS}

The results of this descriptive study indicate that the educational programs designed for SWDs in most of the participating high schools are not what they could be, given the research-based programs available today. First, none of the programs are comprehensive programs that include a number of components, such as intensive-strategy instruction, homework support, research-based instruction in general education courses, and career/vocational preparation. Although some of the programs had one or two components, only one program was utilizing a research-based component (learning strategy instruction), and that component was not in use for large proportions of students' time in class. This was the school that had the highest satisfaction ratings from general education teachers and the students with disabilities. It was one of the two schools in the study in which SWDs were enrolled in general education courses.

In the other seven schools, SWDs were either enrolled in subject-area courses taught by a special education teacher or in subject-area courses taught by a general education teacher (or team-taught by a general and special education teacher) that had been designed specifically for low-achieving students and students with disabilities. Observations of the classes being taught in the special education classroom indicated that they were more like study halls, in which students in several grades worked independently on assignments, than like actual subject-area courses.

These results are cause for concern because they indicate that, in most of the participating schools, SWDs are not receiving the benefits of the results of 25 years of research in the secondary special education field. Of course, the study summarized here focused on only nine high schools, and these schools cannot be considered to be representative of all high schools across the nation. Nevertheless, they are likely to be representative of some high schools across the nation, and IAA researchers, given their experience of observing schools in numerous districts throughout the country and working with staff members in many schools and state departments, believe that they do represent many high schools.

This relatively discouraging portrait of how SWDs are being served in high schools and minimal use of researchbased practices raises some critical questions that must be addressed in future research.

- Are the existing research-based interventions not sufficiently applicable given the conditions present within today's high schools?

- Have teachers not been provided with quality professional development experiences that would enable them to effectively use these innovations?

- Is there a lack of administrative leadership supporting the concentrated use of research-based practices?

- Do teachers perceive a lack of alignment between the demands of statewide outcome assessments and research-based interventions?

These and other questions related to the scalability and sustainability of research-based interventions must be addressed to better understand how to increase the use of instructional practices that will improve student outcomes.

Clearly, much work remains to be done in high schools to set up comprehensive educational programs for SWDs. Schools must have visions of how SWDs are to be educated in such a way that they can succeed in rigorous general education courses, and they must have policies and procedures in place to match those visions. They also must have service-delivery mechanisms for delivering intensive strategy instruction and research-based homework assistance to SWDs so they can truly access the general education curriculum. Further, they have to restructure general education courses and their methods for assigning SWDs to general education courses so these courses become learner-friendly environments for these students and they can feel like valued and accepted members of the learning community.

Research is needed to address these whole-school issues. Ways of ensuring that school staff members create meaningful visions and policies for their schools have to be devised. Teachers need to be trained to use research-validated teaching methods and research-based instructional programs in such a way that they actually implement the programs. Administrators have to be trained to be instructional leaders such that they verbally support the new programs and also insist that the new programs be institutionalized and maintained. Ways for evaluating educational programs have to be devised and put into the hands of administrators. Until all these mechanisms are in place, SWDs likely will continue to flounder at the high school level, and they are not likely to have real access to the general education curriculum. 
The magnitude of the challenges before the educational community has been intensified since passage of the NCLB Act. This legislation creates an even higher and more demanding set of expectations for adolescents with disabilities. Unless conditions are created that will enable SWDs to compete successfully with their normally achieving peers in high schools, the full potential of SWDs as learners in school, as future workers in the global economy, and as contributing community members will not be realized. These findings clearly underscore the notion that researchers must develop and schools must adopt and apply research-based interventions with fidelity in a coordinated, well-orchestrated fashion. In this way, adolescents with disabilities will receive genuine access to the general education curriculum.

\section{REFERENCES}

Alliance for Excellent Education (2002). Every child a graduate: A framework for an excellent education for all middle and high school students. http://www.all4ed.org/policymakers/Every/execsum.html

Brolin, D. E., \& Kokaska, C. J. (1979). Career education for handicapped children and youth. Columbus, $\mathrm{OH}$ : Charles E. Merrill.

Bulgren, J. A., \& Lenz, B. K. (1996). Strategic instruction in the content areas. In D. D. Deshler, E. S. Ellis, \& B. K. Lenz (Eds.). Teaching adolescents with learning disabilities: Strategies and methods (2d ed., pp. 409-473). Denver: Love Publishing.

Bulgren, J. A., Schumaker, J. B., \& Deshler, D. D. (1994). The effects of a recall enhancement routine on the test performance of secondary students with and without learning disabilities. Learning Disabilities Research and Practice, 9(1), 2-11.

Carnine, D. (1995). Trustworthiness, use ability, and accessibility of educational research. Journal of Behavioral Education, 5(3), 251-258.

Carnine, D. (1997). Instructional design in mathematics for students with learning disabilities. Journal of Learning Disabilities, 30(2), 130-141.

Carnine, D., Engelmann, S., Hofmeister, A., \& Kelly, B. (1987). Videodisc instruction in fractions. Focus on Learning Problems in Mathematics, 9(1), 31-52.

Darch, C., \& Carnine, D. (1986). Approaches to teaching learning-disabled students literal comprehension during content area instruction. Exceptional Children, 53(3), 240-246.

Darch, C., Carnine, D., \& Kameenui, E. (1986). The role of graphic organizers and social structure in content-area instruction. Journal of Reading Behavior, 18(4), 275-295.

Deshler, D. D. (2002). Response to "Is learning disabilities just a fancy term for low achievement? A meta-analysis of reading differences between low achievers with and without the label." In R. Bradley, L. Danielson, \& D. Hallahan (Eds.), Identification of learning disabilities. (763-771), Mahwah, NJ: Lawrence Erlbaum.

Englemann, S., \& Carnine, D. (1988). Earth science. Washington, DC: Systems Impact, Inc.

Grossen, B., \& Carnine, D. (1996). Considerate instruction helps students with disabilities achieve world class standards. Teaching Exceptional Children, 28(4), 77-81.

Kameenui, E. J., \& Carnine, D.W. (Eds.). (1998). Effective strategies for accommodating students with diverse learning and curricular needs. Columbus, OH: Merrill.
Kelly, B., Gersten, R., \& Carnine D. (1990). Student error patterns as a function of curriculum design: Teaching fractions to remedial high school students and high school students with learning disabilities. Journal of Learning Disabilities, 23, 23-29.

Kokaska, C. J., Brolin, D. E. (1985). Career education for handicapped individuals ( $2 \mathrm{~d}$ ed.). Columbus, OH: Charles E. Merrill.

Lancaster, P. E., \& Gildroy, P. (1999). Facilitating transitions: Learning in diverse schools and classrooms. In D. Deshler \& J. Schumaker (Eds.), Teaching every adolescent every day. Cambridge, MA: Brookline Books.

Lenz, B. K., Alley, G. R., \& Schumaker, J. B. (1987). Activating the inactive learner: Advance organizers in the secondary content classroom. Learning Disability Quarterly, 10(1), 53-67.

Martin, C. (1999). Net future. New York: McGraw-Hill.

Mercer, C.D., Lane, H.B., Jordan, L., Allsop, D. H., Eisele, M.R. (1996), Empowering teachers and students with instructional choices in inclusive settings. Remedial and Special Education, 17(4), 226-236.

National Research Council (NCR). (1997). National science education standards. Washington, DC: National Academy Press.

Oliver, R.W. (1999). The shape of things to come. New York: McGraw-Hill.

Rifkin, J. (1995). The end of work: The decline of the global labor force and the dawn of the post-market era. New York: Putnam.

Schumaker, J. B., \& Deshler, D. D. (1992). Validation of learning strategy interventions for students with learning disabilities: Results of a programmatic research effort. In B. Y. L. Wong (Ed.), Contemporary intervention research in learning disabilities: An international perspective (pp. 22-46). New York: Springer-Verlag.

Schumaker, J. B., Deshler, D. D., \& McKnight, P. (2002). Ensuring success in the secondary general education curriculum through the use of teaching routines. In G. Stover, M. R. Shinn, \& H. M. Walker (Eds.), Interventions for achievement and behavior problems. Washington, DC: National Association of School Psychologists.

Sitlington, P. L., Clark, G. M., \& Kolstoe, O. P. (2000). Transition education and services for adolescents with disabilities. Boston: Allyn \& Bacon.

Thurlow, M. L., Elliot, J. L., \& Ysseldyke, J. E. (2003). Testing students with disabilities: Practical strategies for complying with district and state requirements. ( $3 \mathrm{~d}$ ed.). Thousand Oaks, CA: Corwin Press.

Turnbull, R., Rainbolt, K., \& Buchele-Ash, A. (1997). Individuals with disabilities education act: Digest of significance of 1997 amendments. Lawrence, KS: Beach Center on Families and Disability.

Wagner, M., Blackorby, J., \& Hebbeler, K. (1993). Beyond the report card: The multiple dimensions of secondary school performance of students with disabilities. A report from the national longitudinal study of special education students. Menlo Park, CA: SRI International.

Warner, M. M., Schumaker, J. B., Alley, G. R., \& Deshler, D. D. (1980). Learning disabled adolescents in the public schools: Are they different from other low achievers? Exceptional Education Quarterly, 1(2), $27-35$.

\footnotetext{
*This article is based on research supported by grant \#PRH324S990001 from the Office of Special Education Programs. The information presented is the responsibility of the authors and does not necessarily represent the views of the U. S. Department of Education.
} 